Elsevier required licence: (c) 2017. This manuscript version is made available under the CC-BY-NC-ND 4.0 license http://creativecommons.org/licenses/by-nc-nd/4.0/ 
Franco-Trigo L, Hossain LN, Durks D, Fam D, Inglis SC, Benrimoj SI, Sabater-Hernández D. Stakeholder analysis for the development of a community pharmacy service aimed at preventing cardiovascular disease. Res Soc Adm Pharm. 2017;13(3):539-552.

http://dx.doi.org/10.1016/j.sapharm.2016.06.009

\title{
Stakeholder analysis for the development of a community pharmacy service aimed at preventing cardiovascular disease
}

\begin{abstract}
Background: Participatory approaches involving stakeholders across the healthcare system can help enhance the development, implementation and evaluation of health services.

These approaches may be particularly useful in planning community pharmacy services and so overcome challenges in their implementation into practice. Conducting a stakeholder analysis is a key first step since it allows relevant stakeholders to be identified, as well as providing planners a better understanding of the complexity of the healthcare system.

Objectives: The main aim of this study was to conduct a stakeholder analysis to identify those individuals and organisations that could be part of a leading planning group for the development of a community pharmacy service (CPS) to prevent cardiovascular disease (CVD) in Australia.
\end{abstract}

Methods: An experienced facilitator conducted a workshop with 8 key informants of the Australian healthcare system. Two structured activities were undertaken. The first explored current needs and gaps in cardiovascular care and the role of community pharmacists. The second was a stakeholder analysis, using both ex-ante and ad-hoc approaches. Identified stakeholders were then classified into three groups according to their relative influence on the development of the pharmacy service. The information gathered was analysed using qualitative content analysis.

Results: The key informants identified 46 stakeholders, including (1) patient/consumers and their representative organisations, (2) healthcare providers and their professional organisations and (3) institutions and organisations that do not directly interact with patients but organise and manage the healthcare system, develop and implement health policies, pay for healthcare, influence funding for health service research or promote new health initiatives. From the 46 stakeholders, a core group of 12 stakeholders was defined. These were considered crucial to the service's development because they held positions that could drive or inhibit progress. Secondary results of the workshop included: a list of needs and gaps in cardiovascular care $(n=6)$, a list of roles for community pharmacists in cardiovascular 
prevention $(n=12)$ and a list of potential factors $(n=7)$ that can hinder the integration of community pharmacy services into practice.

Conclusions: This stakeholder analysis provided a detailed picture of the wide range of stakeholders across the entire healthcare system that have a stake in the development of a community pharmacy service aimed at preventing CVD. Of these, a core group of key stakeholders, with complementary roles, can then be approached for further planning of the service. The results of this analysis highlight the relevance of establishing multilevel stakeholder groups for CPS planning.

Key words: Stakeholder analysis, stakeholder mapping, community pharmacy services [MeSH], cardiovascular diseases [MeSH], Australia [MeSH], health planning [MeSH]

\section{Synopsis}

This article describes a stakeholder analysis aimed at identifying key individuals and organisations for the development of a community pharmacy service. A total of 46 stakeholders across the whole healthcare system were identified, including patient/consumers and their representative organisations, healthcare providers and their professional organisations and other organisations that do not directly interact with patients but can affect their health. A core group of 12 key stakeholders that could strongly influence the development of the service was also defined. This stakeholder analysis highlights the relevance of establishing multilevel stakeholder groups for enhancing the development and implementation of community pharmacy services. 


\section{Introduction}

Current approaches to health planning underline the importance of involving stakeholders across the healthcare system early in the planning process, in order to overcome challenges in the implementation of health services into practice..$^{1-3}$ According to Varvasovskzky and Brugha, ${ }^{4}$ stakeholders are "actors who have an interest in the issue under consideration, who are affected by the issue, or who - because of their position - have or could have an active or passive influence on the decision-making and implementation processes". Theory ${ }^{5}$ and experience ${ }^{6,7}$ suggest that multilevel stakeholder groups bring different benefits to health-service planning processes, such as in-depth knowledge of the context in which the service will be implemented, innovative ideas, and logistic and financial support. Moreover, the collaboration between stakeholders makes health-service planning more transparent, nurtures networking, increases the translation of research findings into practice, fosters colearning, and develops stakeholders' feelings of ownership on the planned health services. ${ }^{8-}$

${ }^{13}$ As a result of participatory planning approaches, health services and associated reforms of the healthcare system are not only more likely to address the existing or emerging population and system needs, but also to be suitably and efficiently developed, implemented and evaluated. $2,5,10,14$

According to the guidelines for the design of participatory processes, ${ }^{15}$ these processes must be informed by a stakeholder analysis (also called stakeholder mapping). A stakeholder analysis encompasses identifying and assessing the individuals and organisations that have a vested interest or can influence a particular initiative. Thus, stakeholder mapping can be used to generate knowledge about the relevant actors related to a particular issue allowing for a deeper understanding of their relative influence and interest on a problem. Importantly it can also provide useful information on the likely role that they may or can play in solving the problem. As a result, the stakeholders that are critical and crucial for the success of a particular initiative can be clearly determined, and solutions that are feasible and acceptable from multiple perspectives can be found. ${ }^{10,16}$ Due to their usefulness, stakeholder analysis are applied in a variety of sectors (e.g., business management, ${ }^{17}$ public and non-for-profit management, ${ }^{12}$ health management, ${ }^{16}$ health policy, ${ }^{16}$ biosecurity risk, ${ }^{14,18}$ natural resource management research ${ }^{19}$ ). Reed and Curzon $^{10}$ described three different theoretical approaches to stakeholder mapping (i.e., normative, instrumental and descriptive) along with the methods that can be used for identifying and categorising stakeholders, and analysing their relationships. Bryson ${ }^{12}$ described a range of stakeholder identification and analysis techniques classified into 4 broad categories according to their purpose: (1) organizing participation; (2) creating ideas for strategic interventions; (3) building a winning coalition 
around proposal development, review and adoption; and (4) implementing, monitoring and evaluating strategic interventions. Despite their wide use, stakeholder analyses are often undertaken without following a systematic process. ${ }^{19}$ Different methods for data gathering have been described in the literature, including interviews with individuals; structured questionnaires; workshops and focus groups with multiple participants; expert opinions; snowballing sampling; etc. ${ }^{16,19}$ It should be noted that the theoretical approaches, methods and techniques to be used in a particular stakeholder analysis should be selected and adjusted according to the particular purpose of the analysis, the timing in which it is conducted (i.e., stage of the project) as well as the availability of resources. ${ }^{16}$ In order to facilitate the understanding of the complexity of the results of stakeholder analyses, various graphical techniques can be used, including stakeholder maps and matrices. For example, Hernández-Jover et $\mathrm{al}^{18}$ used a stakeholder identification map for the representation of stakeholders and several matrices in which stakeholders were located according to their influence and interest on 3 core issues.

In the context of health service planning, conducting a stakeholder analysis at the onset of the planning process not only clarifies the complexity of the context in which services will be implemented but also avoids the involvement of stakeholders who are not representative..$^{9,10}$ In this regard, a recent analysis on current service development practices highlights the role of stakeholder maps in explicitly conducting an early exploration of the 'ill-defined problem space' before generating a particular solution. ${ }^{20}$ Despite its importance, stakeholder mapping is poorly described in the health service literature, where, interestingly, a number of articles reporting the development of health programs that used participatory planning approaches lack this type of analysis. ${ }^{6,21-23}$ Without such information, it is difficult to understand the reasons behind the involvement of each stakeholder or to be certain that the key stakeholders have been engaged. An appropriate description of stakeholder analysis ${ }^{24,25}$ meets the recommendations for comprehensively reporting participatory processes ${ }^{6}$ and increases the transparency of such processes, allowing for their evaluation and improvement.

Participatory planning approaches are useful in pharmacy practice, where the development, evaluation and implementation of services, and the integration of community pharmacists into the healthcare team still remains a challenge. ${ }^{26,27}$ The planning process and development of CPSs is further discussed elsewhere along with some general information about how research can inform such a process. ${ }^{27} \mathrm{~A}$ stakeholder analysis is a type of study that should be conducted at the outset of the CPS planning process to inform the group of stakeholders that may be involved in such a process. A multilevel stakeholder group may 
help understand and address the complexities of the healthcare system in which community pharmacy services (CPSs) need to be embedded, and so improve the implementation of those services. ${ }^{27,} 28$ A specific area in which CPSs are seen to be particularly relevant is in the prevention of cardiovascular disease (CVD), ${ }^{29}$ which is a major public health problem. ${ }^{30}$, ${ }^{31}$ According to the World Health Organization, interventions at the primary-care level are considered to be the optimal approach to reverse the progression of CVD, prevent long-term complications, and reduce the use of associated healthcare resources. ${ }^{31}$ Community pharmacists are highly accessible healthcare professionals at the primary-care level and their positive impact on the control of cardiovascular risk factors has already been shown. ${ }^{29}$ In order to promote the development and further implementation of a CPS aimed at preventing CVD in Australia, this study conducted a stakeholder analysis to identify those key stakeholders that could be part of a leading planning group. As a secondary objective, current gaps and needs in cardiovascular care and the role of community pharmacists were explored.

\section{Material and methods}

Study design. A workshop was carried out at the University of Technology, Sydney (UTS), with a group of 8 key informants. A 'descriptive' theoretical approach, which aims to understand the relationships between a particular issue and its stakeholders, ${ }^{19}$ was adopted in the stakeholder analysis. The design of the study was based on the approaches proposed by Varvasovszky and Brugha ${ }^{4}$ and Reed et al. ${ }^{19}$ To stimulate discussions Varvasovszky and Brugha's ${ }^{4}$ suggestions of face-to-face discussions between a broad group of informants (i.e. insiders and outsiders to the project) with different backgrounds, expertise and roles within the healthcare system were used. This provided a comprehensive view of the Australian healthcare system, neutralised individual biases and questioned individually held assumptions. All participants were potential stakeholders to the project, which allowed for enhancing the quality and credibility of both the analysis and the results as suggested by Reed et al. ${ }^{19}$ Key informants were purposively selected because they had complementary profiles and were potential stakeholders in the project. Key informants' profiles encompassed community pharmacy managers/owners with experience in service provision and connected to pharmacy professional organisations; an experienced cardiologist; a nurse/cardiovascular researcher related to different cardiovascular and nurse associations; a hospital pharmacist and executive at a governmental advisory organisation promoting quality use of medicines; an executive of a cardiovascular network with experience in the pharmacy industry; and academics/researchers with wide experience in pharmacy practice/service research. 
Workshop organisation. The general structure of the workshop can be seen in Fig. 1 and included two main activities:

Activity 1: Exploring the needs and gaps in cardiovascular care and the roles of community pharmacists. This preliminary discussion was used to prompt key informants to share ideas and feel comfortable in order to establish a common ground for the next activity regarding the identification of stakeholders. To facilitate the identification of gaps in cardiovascular care, participants were given a handout (Appendix 1) containing a list of cardiovascular risk factors and diseases (based on WHO Global Atlas on cardiovascular disease prevention and control $^{31}$ ). The handout also contained a list of potential roles of community pharmacists in cardiovascular care (informed from the literature ${ }^{29}$ ), with the intention of stimulating discussion between key informants and prompting some ideas.

Activity 2: Stakeholder identification and classification. The key informants were asked to identify stakeholders with a vested interest in the development of a CPS aimed at preventing CVD. To drive the exercise, the following definition of stakeholder was provided: "any individual or organisation that can be directly or indirectly affected by, have an influence on, or have an interest in the development of a CPS aimed at the prevention of cardiovascular diseases" (adapted from Varvasovskzky and Brugha ${ }^{4}$ ). The identification of stakeholders was made using both ex-ante and ad-hoc approaches. These approaches are complementary and the combination of both enables more information to be collected. ${ }^{10}$ The ex-ante approach recommends identification of stakeholders in advance. Relevant stakeholders were identified by researchers from the literature prior to the workshop. These identified stakeholders, grouped in categories as adapted from Preskill and Jones, ${ }^{5}$ were used in the workshop as examples in a handout provided to key informants (Table 1). In contrast, the ad-hoc approach does not provide probable stakeholders a priori but encourages stakeholder identification by key informants using questions. For this purpose, questions adapted from Gilmour and Beilin, ${ }^{14}$ were projected onto a slide (Table 1). The identified stakeholders were then classified into three groups according to the relative influence that they were considered to have on the development of the CPS (adapted from Covey's circle of concern/circle of influence ${ }^{32}$ ):

1. Control: stakeholders who have the ability to control the development of the service, can prevent it from progressing or help make it happen.

2. Influence: stakeholders who have the ability to influence the development of the service - i.e. have less control but are still important to making it happen. 
3. Interest/concern: stakeholders who may be interested in or concerned with the service but will not significantly influence whether or not the project goes ahead.

Following current recommendations for designing public participation processes, ${ }^{15}$ discussions between key informants regarding the classification of stakeholders were held until consensus was reached to ensure that the key stakeholders that need to be involved in the first phase of the CPS planning process were identified.

In order to enhance the future feasibility of the project, some geographical boundaries were set (i.e., questions to the key informants were focused on New South Wales, Australia). This decision was made based on existing frameworks for health service/program planning. ${ }^{1,27,33}$ These frameworks suggest services/programs should be developed and piloted (for optimisation) in limited geographical areas before further impact and outcome evaluation and scaling-up. An external, experienced facilitator conducted the workshop. The facilitator was experienced in systems thinking, community engagement and stakeholder mapping. While she did not have experience with healthcare in particular, she did have extensive experience in designing and facilitating workshops with stakeholders across diverse disciplinary fields and industry sectors including the energy, mining and education sectors. The facilitator ensured that goals of the meeting were met within the designated timeframe; the group did not diverge from the set agenda; both dominant and withdrawn participants were managed to ensure all voices were heard; the composition of groups when participants were separated for discussion was balanced; and findings were validated through group feedback processes at the end of the workshop. Two researchers took notes and the workshop was audiotaped and transcribed. Butchers paper and Post-it notes were used during the activities and collected at the end of the workshop. The UTS Human Research Ethics Committee approved the study (UTS HREC REF NO. 2015000349) and participants were provided with an information sheet and signed a consent form.

Data analysis. The information sources (i.e. transcripts, researchers' notes, Post-it notes and butchers paper) were analysed using qualitative content analysis, which allowed categories to emerge from the data and acknowledged the significance of the context in which the analysed information was generated. ${ }^{34,35}$ Qualitative content analysis has been found to be a useful analytical technique in health research. ${ }^{36-38}$ This type of analysis is appropriate to describe the meaning of the answers of a wide variety of questions in a systematic way. It focusses on extracting categories from the data and is a flexible technique that can be used with both inductive and deductive approaches. ${ }^{35,39}$ A deductive approach using a 4-step coding process was followed. First, one reviewer read through the information sources several times and created a preliminary list of prior categories. Second, the text was coded 
according to these categories; when relevant information could not be coded into an existing category, a new category was created. Third, categories were reviewed to either create subcategories or merge categories that addressed similar issues. The results derived from this process were discussed with a second researcher in order to improve the interpretation of the information and the credibility of the results. The trustworthiness of the qualitative content analysis was assured by addressing credibility, dependability and transferability of the data. ${ }^{40}$ Credibility was reinforced by choosing participants with various perspectives and experiences, selecting how to gather data and verifying that categories covered the whole data during the analysis. Dependability was assured by bringing participants together in a workshop and collecting data at a specific point of time to avoid the risk of inconsistency in the data due to the phenomena of interest changing over time. Finally, regarding transferability of key themes, a detailed description of the characteristics of participants, methodology, and findings was presented in order to help readers elucidate the extent to what the findings can be transferred to a different context. Microsoft Excel 2010.Ink was used to manage and analyse the data.

\section{Results and discussion}

Although the activities of the workshop were planned in a specific order, the results section is organised to first address the primary objective of the study.

\section{Identifying and mapping stakeholders}

Key informants identified 46 stakeholders across the healthcare system. A detailed stakeholder map is shown in Fig. 2, where three main groups can be differentiated:

1. Individual patients/consumers and their representative organisations.

2. Healthcare professionals who interact with patients on their journey through the healthcare system (e.g. community pharmacists, general practitioners, nurses, cardiologists), and their professional organisations/associations that have the capacity to influence both the individuals within their collectives and health policy.

3. Institutions and organisations that do not directly interact with patients but can affect their health (e.g. governmental institutions, cardiovascular leading/scientific organisations, universities, pharmaceutical industry, insurers). This third group organises and manages the healthcare system, develops and implements health policies, pays for healthcare, influences funding for health service research, and promotes new health initiatives. Further details about the roles of Australian government-related stakeholders can be found in Appendix 2 . 
To the best of our knowledge, this is the first stakeholder analysis that uses a systematic approach with potential stakeholders to inform the development of a CPS. Recently, Vozikis et $\mathrm{al}^{28}$ used a stakeholder analysis to research the complexity of the system in which community pharmacists are embedded focussing on health policy, while the objective of the stakeholder analysis in this study was health service development. According to results of the stakeholder identification process, it can be argued that CPS planning must involve a wide range of stakeholders with complementary roles within the healthcare system to facilitate the development and implementation of those services and so the integration of community pharmacists into the primary healthcare team. In fact, according to key informants, not considering the complexity of the healthcare system in which CPSs will be implemented and the wide array of stakeholders (and their personal interests and power) may partly explain why previous experiences aiming at implementing these services have failed (quotes 1 and 2, Table 2). As argued by several authors,, ${ }^{41-43}$ the early engagement and input of a diversity of stakeholders in the planning process is crucial to successfully implement highly valuable health services. In fact, current co-design approaches involve service participants (e.g. patients, carers, health-service providers) in early planning stages to enhance existing health services, ${ }^{44}$ develop new ones, ${ }^{45}$ or adapt evidence-based interventions from other contexts. ${ }^{46}$ Beyond the contribution of service participants, highlevel stakeholders (e.g. policy makers, managers, payers) bring important insights to the process not only by sharing their broad knowledge about the healthcare system (e.g. organisation, regulation, resources) but also by providing logistic and financial support. ${ }^{6}$ The relevance and usefulness of participatory approaches has begun to be reported in CPS planning in Canada and New Zealand. ${ }^{6,47}$

When the key informants estimated the relative influence of each stakeholder on the development of a CPS, 19 were considered to have "control" over the situation, 16 to have "influence" and 11 to have an "interest/concern" (Fig. 2). Among the 19 included in the "control group", key informants agreed on a "core group of 12 stakeholders" (Fig. 2) that were considered crucial for ensuring the service's development, because they held positions that could drive (or inhibit) the project's progress (quotes 3 to 6, Table 2). The key informants also commented that if this core group of stakeholders could work together, other stakeholders would join the process (quote 3, Table 2). Specifically, the 12 stakeholders that were considered the core group were: Primary Healthcare Networks, Agency for Clinical Innovation, Chronic Cardiovascular Clinical Expert Reference Group, Office for Health and Medical Research, Local Health Districts \& Specialty Networks, Heart Foundation, Pharmacy Guild of Australia, Australian Medical Association, The Royal Australian College of General Practitioners, individual patients, patient groups/organisations (including disease-oriented), 
and Consumer Health Forum of Australia. The configuration of this group encompasses different key profiles, such as end-beneficiaries of the service and healthcare professionals, leading cardiovascular organisations, health-system managers, and health policy makers and regulators, who can be also payers. Interestingly, these stakeholder profiles have been shown to be the main promoters of service development projects in mental health. ${ }^{20}$ As recommended by the guidelines for designing public participation processes, ${ }^{15}$ by reaching this agreement, this stakeholder analysis ensured that the key stakeholders that should be involved at this stage of the process were identified. From a planning perspective, the identification of a core group of stakeholders has allowed for the prioritisation of stakeholders that will be initially approached in future workshops aimed at developing a vision (i.e. visioning exercise ${ }^{48}$ ) on how to further integrate CPS to enhance cardiovascular care.

According to the key informants, the relative importance of the identified stakeholders may change depending on the stage of a patient's journey (i.e. settings, care processes) that the service will be focused on (quote 7, Table 2). This observation is consistent with existing stakeholder theory, ${ }^{10,17,49}$ which states that the influence, interest or involvement of stakeholders in a project may vary depending on several circumstances. For example, planning a CPS addressing the needs of patients being discharged from hospital might not consider the same stakeholders as a service addressing the promotion of healthy lifestyle habits in healthy people. Aside from this example, two other situations were highlighted in this mapping exercise. First, at this stage of the planning process, the health problem was still too broad (i.e. encompassing a wide spectrum of conditions, risk factors and different levels of prevention), which resulted in a similarly broad group of stakeholders being identified. In future, the definition of a specific issue and target population within the cardiovascular spectrum will narrow the group of stakeholders. When the boundaries of the service have been clearly established, it will be advisable to explore in depth the role, the interests, and existing relationships between, the stakeholders. ${ }^{10,12,14,19}$ Second, this stakeholder analysis focused on the development of the service, mainly encompassing the theoretical design of the service and piloting for optimisation. ${ }^{27}$ According to health planning approaches, the relative interest, influence or involvement of different stakeholders throughout the stages of the planning process (i.e. development, implementation, evaluation) may change depending on the aims of each stage. ${ }^{2,3}$ That is to say, the configuration of planning groups should be regularly examined to both ensure that the right stakeholders are involved at each stage of the planning process, and enable new members to join the group and so bring new ideas and enthusiasm to the discussion. ${ }^{33}$ As a result, stakeholder analysis should be an ongoing exercise that needs to be conducted several times throughout the 
service-planning process. ${ }^{10,14}$ This will allow suitable changes in the composition of planning groups to align with the needs of the planning process.

Although a first comprehensive stakeholder analysis should be conducted at the outset of any CPS planning process, occasionally resource-, time- or funding constraints can limit the breadth and depth of this analysis. ${ }^{4}$ If logistics do not allow for direct interaction with stakeholders to conduct a stakeholder mapping, planners still need to approach the identification of stakeholders. Different methods can be used including: analysing documents and literature relevant to the phenomenon of interest, information published in the websites of the organisations that are related to the topic, gathering expert opinions, or using questionnaires. ${ }^{4,19}$ The results of this study can help pharmacy-service planners identify and select relevant stakeholders. This is because the present stakeholder analysis can frame and provide insight into the individual profiles, roles, settings, system organisations etc. that can be involved in other CPS-planning processes. Finally, in order to design and conduct this study, the project team engaged cross disciplinary input, collaborating with social scientists with expertise in qualitative methods, stakeholder mapping and facilitation skills. As far as we are aware, training in stakeholder mapping techniques is not typically available for pharmacy researchers. We suggest that more attention should be given to this training when the education of researchers in service development is outlined, since the stakeholder analysis is a very first step of the planning process of a service and informs the group of stakeholders that should lead and manage such a process.

\section{Needs or gaps in cardiovascular care and potential roles of community pharmacies}

With regard to the secondary objective of this study, key informants disclosed several gaps or needs in current cardiovascular care practice and associated roles of community pharmacists in the prevention and management of CVD (Table 3). This information rounds out the stakeholder identification process, providing preliminary insight about the problem to be addressed and how community pharmacists can be involved in such a problem. ${ }^{19}$ In the future, these secondary results can be used to inform early planning steps and discussions aimed at defining a specific problem situation to be targeted by the CPS. It should be noted that the roles of community pharmacists identified by the key informants in this study have already been reported (and claimed) in previous studies conducted in Australia, ${ }^{50,51}$ which emphasises the existing need to develop and implement cardiovascular CPSs into primary care practice.

As part of the same discussion, key informants addressed several factors that can hinder the integration of CPSs into practice (i.e., barriers) (Table 4). Although the list of factors in Table 
4 is not comprehensive, it is consistent with the findings of previous studies that assessed the barriers to the expansion of the community pharmacist's role in Australia ${ }^{51}$ or the use of community pharmacy public health services in England. ${ }^{52}$ Key informants put special emphasis on the poor coordination between healthcare processes and services within the healthcare system and the poor communication and collaboration between healthcare professionals (e.g. community pharmacists and general practitioners). Once again, the identified barriers highlight the importance of involving multilevel stakeholder groups in planning CPSs. This is because most of the barriers may require strategies and interventions targeting different organisations, settings, processes and individuals across the healthcare system to be suitably addressed. ${ }^{53,54}$

Limitations. The information gathered in this study represents a 'snapshot' of a system that is continuously changing (i.e., the obtained information is provisional). There is a recommendation of repeating the stakeholder analysis throughout the planning process in order to update results and so ensure that the right stakeholders are involved and that new members are enabled to join the group. ${ }^{10,14} \mathrm{~A}$ deeper understanding of the roles and relationships of the stakeholders was not considered as this change as the planning process proceeds to more definite service definition. It should be noted that patient carers, family members and friends were not specifically named in this mapping exercise. Different authors consider this "interpersonal support network" of patients essential stakeholders in participatory research approaches ${ }^{8}$ and the co-design of health services. ${ }^{55-58}$ "Carers or loved ones" are also an intrinsic part of the definition of "patient" provided by the King's Fund toolkit for experience-based co-design. ${ }^{56}$ For these reasons, they have been added as part of the list of stakeholders in this exercise.

\section{Conclusions}

This stakeholder analysis provided a detailed picture of the wide range of individuals and organisations that have a stake in the development of a CPS aimed at preventing CVD. Stakeholders were distributed across the whole healthcare system and were considered to have different influences in the development of the service. These results underline the need for multilevel stakeholder groups to deal with the complexity of the healthcare system in which CPSs are to be embedded and so facilitate the integration of community pharmacists into the primary healthcare team. A core group of stakeholders with complementary roles was also defined. This group can ensure the development of the service and strongly influence progress. Stakeholders in the core group will be approached to collaboratively plan the proposed community pharmacy service. Finally, useful information concerning the gaps and needs in current cardiovascular care, the role of community pharmacists in 
cardiovascular prevention and the factors that can affect the implementation of a community pharmacy service, was obtained.

\section{Acknowledgements}

We would like to acknowledge the key informants for their disinterested collaboration in this research, and also Ms Melissa Jackson, who worked with us on the design and delivery of the workshop.

This work is part of the PhD of Lucía Franco-Trigo, who was awarded a University of Technology Sydney (UTS) President's Scholarship and a UTS International Research Scholarship. This PhD is part of a joint PhD degree program between the UTS and the University of Granada (PhD program in 'Clinical Medicine and Public Health').

Funding for this research has been provided by a UTS Chancellor's postdoctoral fellowship awarded to Dr Daniel Sabater-Hernandez, who is the principal PhD supervisor and chief investigator for this project (ID number: 2013001605).

Sally C Inglis is supported by a Cardiovascular Research Network Life Science Research Fellowship from the National Heart Foundation of Australia and the NSW Office for Health and Medical Research (CR 11S 6226). 


\section{References}

1. Craig P, Dieppe P, Macintyre S, Michie S, Nazareth I, Petticrew M. Developing and evaluating complex interventions: the new Medical Research Council guidance. BMJ. 2008;337:a1655.

2. Bartholomew LK, Parcel GS, Kok G, Gottlieb NH, Fernández ME. Planning health promotion programs: An Intervention Mapping approach. 3rd ed. San Francisco, CA: Jossey-Bass; 2011.

3. Green L, Kreuter M. Health program planning: An educational and ecological approach. 4th ed. Boston: McGraw-Hill; 2005.

4. Varvasovszky Z, Brugha R. A stakeholder analysis. Health Policy Plann. 2000;15:338-345.

5. Preskill $\mathrm{H}$, Jones N. A practical guide for engaging stakeholders in developing evaluation questions. Robert Wood Johnson Foundation Evaluation Series: Robert Wood Johnson Foundation; 2009.

6. Lalonde L, Goudreau J, Hudon É, et al. Development of an interprofessional program for cardiovascular prevention in primary care: A participatory research approach. SAGE Open Med. 2014;2:2050312114522788.

7. Hinchcliff $\mathrm{R}$, Greenfield D, Braithwaite J. Is it worth engaging in multi-stakeholder health services research collaborations? Reflections on key benefits, challenges and enabling mechanisms. Int J Qual Health Care. 2014;26:124-128.

8. Cargo M, Mercer SL. The value and challenges of participatory research: strengthening its practice. Annu Rev Public Health. 2008;29:325-350.

9. Luyet V, Schlaepfer R, Parlange MB, Buttler A. A framework to implement Stakeholder participation in environmental projects. J Environ Manag. 2012;111:213219.

10. Reed M, Curzon R. Stakeholder mapping for the governance of biosecurity: a literature review. J Integr Environ Sci. 2015;12:15-38.

11. Glasgow RE, Emmons KM. How can we increase translation of research into practice? Types of evidence needed. Annu Rev Public Health. 2007;28:413-433.

12. Bryson JM. What to do when stakeholders matter: stakeholder identification and analysis techniques. Public Manag Rev. 2004;6:21-53.

13. Green LW. Making research relevant: if it is an evidence-based practice, where's the practice-based evidence? Fam Pract. 2008;25:i20-i24.

14. Gilmour J, Beilin R. Stakeholder mapping for effective risk communication. Vol 2015: Australian Centre for Excellence in Risk Analysis; 2007. Available at: www.acera.unimelb.edu.au/materials/core.html [Accessed 23/04/15]. 
15. Bryson JM, Quick KS, Slotterback CS, Crosby BC. Designing Public Participation Processes. Public Adm Rev. 2013;73:23-34.

16. Brugha R, Varvasovszky Z. Stakeholder analysis: a review. Health Policy Plann. 2000;15:239-246.

17. Freeman RE. Strategic Management: a Stakeholder Approach. Boston, Massachusetts: Pitman; 1984.

18. Hernandez-Jover M, Gilmour J, Schembri N, et al. Use of stakeholder analysis to inform risk communication and extension strategies for improved biosecurity amongst small-scale pig producers. Prev vet med. 2012;104:258-270.

19. Reed M, Graves A, Dandy N, et al. Who's in and why? A typology of stakeholder analysis methods for natural resource management. J Environ Manage. 2009;90:1933-1949.

20. Jun GT, Morrison C, Clarkson PJ. Articulating current service development practices: a qualitative analysis of eleven mental health projects. BMC Health Serv Res. 2014;14:20.

21. Rutten GM, Harting J, Bartholomew LK, et al. Development of a theory-and evidence-based intervention to enhance implementation of physical therapy guidelines for the management of low back pain. Arch Public Health. 2014;72:1-12.

22. Wheeler A, Fowler J, Hattingh L. Using an intervention mapping framework to develop an online mental health continuing education program for pharmacy staff. $J$ Contin Educ Health Prof. 2013;33:258-266.

23. Heinen MM, Bartholomew LK, Wensing $M$, van de Kerkhof $P$, van Achterberg $T$. Supporting adherence and healthy lifestyles in leg ulcer patients: systematic development of the Lively Legs program for dermatology outpatient clinics. Patient Educ Couns. 2006;61:279-291.

24. Hyder A, Syed S, Puvanachandra $P$, et al. Stakeholder analysis for health research: case studies from low-and middle-income countries. Public Health. 2010;124:159166.

25. Makan A, Fekadu A, Murhar V, et al. Stakeholder analysis of the Programme for Improving Mental health carE (PRIME): baseline findings. Int J Ment Health Syst. 2015;9:1-12.

26. Mossialos E, Courtin E, Naci H, et al. From "retailers" to health care providers: Transforming the role of community pharmacists in chronic disease management. Health Policy. 2015;119:628-639.

27. Sabater-Hernández D, Moullin J, Hossain L, et al. Intervention mapping for developing pharmacy-based services and health programs: A theoretical approach. Am J Health-Syst Pharm. 2016;73:156-164. 
28. Vozikis A, Stavropoulou L, Patrinos GP. Community Pharmacists' Strategies in Greece: An Assessment of the Policy Environment and the Mapping of Key Players. Health. 2015;7:1560.

29. Sabater-Hernández D, Sabater Galindo M, Fernandez-Llimos F, et al. A systematic review of evidence-based community pharmacy services aimed at the prevention of cardiovascular diseases. J Manag Care Spec Pharm 2016;22(6):699-713.

30. World Health Organisation. Cardiovascular diseases (CVDs). Fact Sheet N317, 2015. Available at: http://www.who.int/mediacentre/factsheets/fs317/en/\# [Accessed 26/02/2016]

31. Mendis S, Puska P, Norrving B. Global atlas on cardiovascular disease prevention and control: World Health Organization; Geneva 2011.

32. Covey S. The 7 habits of highly effective people: Powerful lessons in personal change. New York: Simon \& Schuster; 2013.

33. McKenzie JF, Neiger BL, Thackeray R. Planning, implementing, \& evaluating health promotion programs: A primer. 5th ed. San Francisco, CA: Pearson Higher; 2009.

34. Bryman A. Social research methods. 4th ed. New York: Oxford university press Inc; 2012.

35. Cho JY, Lee E-H. Reducing confusion about grounded theory and qualitative content analysis: similarities and differences. Qual Rep. 2014;19:1.

36. Golla H, Galushko M, Pfaff H, Voltz R. Unmet needs of severely affected multiple sclerosis patients: The health professionals' view. Palliat Med. 2012;26:139-151.

37. Niemi M, Thanh HT, Tuan T, Falkenberg T. Mental health priorities in Vietnam: a mixed-methods analysis. BMC health Serv Res. 2010;10:257.

38. Schneider N, Lueckmann SL, Kuehne F, Klindtworth K, Behmann M. Developing targets for public health initiatives to improve palliative care. BMC public health. 2010;10:1.

39. Bengtsson M. How to plan and perform a qualitative study using content analysis. NursPlus Open. 2016;2:8-14.

40. Graneheim UH, Lundman B. Qualitative content analysis in nursing research: concepts, procedures and measures to achieve trustworthiness. Nurs Educ Today. 2004;24:105-112.

41. Grant RW, Schmittdiel JA. Building a career as a delivery science researcher in a changing health care landscape. J Gen Intern Med. 2015;30:880-882.

42. Guise J-M, O'Haire C, McPheeters M, et al. A practice-based tool for engaging stakeholders in future research: a synthesis of current practices. J Clin Epidemiol. 2013;66:666-674. 
43. Schmittdiel JA, Grumbach K, Selby JV. System-based participatory research in health care: an approach for sustainable translational research and quality improvement. Ann Fam Med. 2010;8:256-259.

44. Boyd H, McKernon S, Mullin B, Old A. Improving healthcare through the use of codesign. N Z Med J. 2012;125:76-87

45. Wherton J, Sugarhood P, Procter R, Hinder S, Greenhalgh T. Co-production in practice: how people with assisted living needs can help design and evolve technologies and services. Implement Sci. 2015;10:75.

46. Waugh A, Austin A, Manthorpe J, et al. Designing a complex intervention for dementia case management in primary care. BMC Fam Pract. 2013;14:1.

47. Ministry of Health. Draft Pharmacy Action Plan 2015-2020: For consultation. Wellington: Ministry of Health; 2015.

48. Boomer C, Collin I, McCormack B. 'I have a dream': A process for visioning in practice development. Pract Dev Health Care. 2008;7:70-78.

49. Mitchell RK, Agle BR, Wood DJ. Toward a theory of stakeholder identification and salience: Defining the principle of who and what really counts. Acad Manage Rev. 1997;22:853-886.

50. George J, McNamara K, Stewart K. The roles of community pharmacists in cardiovascular disease prevention and management. Australas Med J. 2011;4:266272.

51. McMillan SS, Wheeler AJ, Sav A, et al. Community pharmacy in Australia: a health hub destination of the future. Res Soc Admin Pharm. 2013;9:863-875.

52. Saramunee K, Krska J, Mackridge A, Richards J, Suttajit S, Phillips-Howard P. How to enhance public health service utilization in community pharmacy?: General public and health providers' perspectives. Res Soc Admin Pharm. 2014;10:272-284.

53. Moullin JC, Sabater-Hernández D, Fernandez-Llimos F, Benrimoj SI. A systematic review of implementation frameworks of innovations in healthcare and resulting generic implementation framework. Health Res Policy Syst. 2015;13:5.

54. Powell BJ, McMillen JC, Proctor EK, et al. A compilation of strategies for implementing clinical innovations in health and mental health. Med Care Res Rev. 2012;69:123-157.

55. Paton N, Callander R, Cavill M, Ning L, Weavell W. Collaborative quality improvement: consumers, carers and mental health service providers working together in service co-design. Australas Psychiatry. 2013;21:78-79.

56. The King's Fund. Experience-based co-design toolkit. 2013. Available at: http://www.kingsfund.org.uk/projects/ebcd [Accessed 09/02/2016] 
57. Bate $P$, Robert $G$. Experience-based design: from redesigning the system around the patient to co-designing services with the patient. Qual Saf Health Care. 2006;15:307310.

58. Tollyfield R. Facilitating an accelerated experience-based co-design project. $\mathrm{Br} \mathrm{J}$ Nurs. 2014;23. 
Table 1. Information provided to key informants to guide and support the stakeholder analysis

1. Ex-ante approach: Stakeholder categories (adapted from Preskill and Jones ${ }^{5}$ )

\begin{tabular}{|l|l|}
\hline Stakeholder category & Examples \\
\hline $\begin{array}{l}\text { End-beneficiaries and } \\
\text { representative organisations }\end{array}$ & $\begin{array}{l}\text { Patients, patient associations, consumer's groups, community } \\
\text { leaders, community based-organisations, non-governmental } \\
\text { organisations etc. }\end{array}$ \\
\hline $\begin{array}{l}\text { Healthcare providers (and } \\
\text { other staff), health } \\
\text { system/service managers } \\
\text { and professional } \\
\text { organisations }\end{array}$ & $\begin{array}{l}\text { Pharmacists (and pharmacy staff), pharmacy managers/owners, } \\
\text { general practitioners, specialist, nurses, system managers, } \\
\text { executives, board of directors, advisory boards, etc. }\end{array}$ \\
\hline $\begin{array}{l}\text { Experts, researchers and } \\
\text { health service planners }\end{array}$ & $\begin{array}{l}\text { Experts in the health problem, community pharmacy, health } \\
\text { system, business, strategic planning, etc. } \\
\text { Universities, research groups, planning groups, evaluation bodies, } \\
\text { etc. }\end{array}$ \\
\hline $\begin{array}{l}\text { Health policymakers, } \\
\text { regulators and payers }\end{array}$ & $\begin{array}{l}\text { Federal, state or local government agencies, advocacy } \\
\text { organisations, insurance companies, etc. }\end{array}$ \\
\hline Follaborators & Funders/donors, industry, media, educators, etc. \\
\hline
\end{tabular}

2. Ad-hoc approach: Questions to trigger the identification of stakeholders (adapted from Gilmour and Beilin ${ }^{14}$ )

- Who may be affected by this?

- Who might influence the change?

- Who has the power to make/stop it happening?

- Where might funding/financing come from?

- Who are potential allies or opponents?

- What coalitions might build around this issue? 
Table 2. Selected quotes regarding the stakeholder analysis

Quote 1: "It really does make a difference to get people in on the ground level very early and for me, brought up the, it highlighted the complexity of the system, and how many different people you have to actually bring to the table..."

Quote 2: "...it still makes me realise why a lot of these projects never end up being successful, because there are too many people who got too much control and influence"

Quote 3: "If you had the [organisation A], if you had the [organisation B], you had the [organisation C], the [organisation D] and the [organisation E]. If you had those five on the table, everybody else would just come..."

Quote 4: "They [organisations A, B, C, D and E] could make or break the project."

Quote 5: "I think the good thing about the [organisation F] is that it comes without its own baggage"

Quote 6: "I think that having a project that's actually evolved in conjunction with the consumer is actually going to be what makes this ultimately successful, because that's actually the end user. If you don't take their wishes into consideration, forget the project."

Quote 7: "I think the relative importance of them will change depending where you position the program in the [care] process..." 
Table 3. Needs or Gaps in cardiovascular care and potential roles of community pharmacists*

\begin{tabular}{|c|c|}
\hline $\begin{array}{l}\text { Needs and gaps in current cardiovascular } \\
\text { care }\end{array}$ & Associated role of community pharmacists \\
\hline $\begin{array}{l}\text { Enhance the knowledge and use of } \\
\text { medicines by patients. } \\
\text { (Related quotes in appendix 3: } 1 \text { and 2) }\end{array}$ & $\begin{array}{l}\text { - Educating patients to optimise medication use and } \\
\text { knowledge } \\
\text { - Conducting medication reviews (e.g., discharge } \\
\text { medication reviews and home medication } \\
\text { reviews), checking drug interactions and toxicities } \\
\text { - Monitoring and promoting medication adherence } \\
\text { (especially when diseases are asymptomatic) } \\
\text { - Performing dose administration aids } \\
\text { (Related quotes in appendix 3: } 19 \text { to 23) }\end{array}$ \\
\hline $\begin{array}{l}\text { Enhance the availability of updated lists of } \\
\text { patients' medications } \\
\text { (Related quotes in appendix 3: } 3 \text { and 4) }\end{array}$ & $\begin{array}{l}\text { - Elaborating patients' medication profile (or } \\
\text { checking whether it has been provided by the } \\
\text { general practitioner) } \\
\text { (Related quotes in appendix 3: } 24 \text { to } 26 \text { ) }\end{array}$ \\
\hline $\begin{array}{l}\text { Enhance patients awareness and } \\
\text { understanding of cardiovascular disease } \\
\text { (Related quotes in appendix 3: } 5 \text { to11) }\end{array}$ & $\begin{array}{l}\text { - Educating patients to enhance their awareness } \\
\text { and knowledge on their diseases } \\
\text { - Empowering patients to better manage their } \\
\text { diseases (i.e., enhancing self-management) } \\
\text { (Related quotes in appendix 3: } 27 \text { and 28) }\end{array}$ \\
\hline $\begin{array}{l}\text { Prevention or delay of the onset of the } \\
\text { disease or associated complications } \\
\text { (Related quotes in appendix 3: } 12 \text { to 14) }\end{array}$ & $\begin{array}{l}\text { - Promoting healthy habits } \\
\text { - Providing immunisation for people at risk (e.g. flu } \\
\text { vaccination) } \\
\text { (Related quote in appendix 3: 29) }\end{array}$ \\
\hline $\begin{array}{l}\text { Improve patient use and accessibility to } \\
\text { health services (especially in rural areas) } \\
\text { (Related quotes in appendix 3: } 15 \text { to 18) }\end{array}$ & $\begin{array}{l}\text { - Providing services in rural areas } \\
\text { - Encouraging patients to visit other healthcare } \\
\text { professionals and services when needed. } \\
\text { (Related quote in appendix 3: } 30 \text { ) }\end{array}$ \\
\hline $\begin{array}{l}\text { Enhance early diagnose and treatment of } \\
\text { cardiovascular risk factors }\end{array}$ & $\begin{array}{l}\text { - Screening high risk patients and refer them to the } \\
\text { GPs for diagnosis when needed } \\
\text { (Related quote in appendix 3: 31) }\end{array}$ \\
\hline
\end{tabular}


Table 4. Factors that can hinder the integration of cardiovascular community pharmacy services into practice* $^{*}$

- Poor coordination between healthcare processes and services (e.g. lack of medication review or follow-up appointments after patients being discharged from hospital to community). The poor coordination between healthcare processes and services is aggravated by the fact that care providers are not usually aware of the patients' previous journey through the system and the availability of cardiovascular services/programs (this latter problem is also shared by patients). (Related quotes in appendix 3: 32 and 33)

- Unavailability of information management systems containing comprehensive patients' medical records and medication lists. This results in an incomprehensive 'picture' of the patient that hinders clinical evaluation, medication review, etc. (Related quote in appendix 3 : 34)

- Absence of a model of collaboration and communication between healthcare professionals (i.e., all of them working in silos). (Related quotes in appendix 3: 35 to 39)

- Lack of continuity of care (i.e., patients attending different pharmacies and medical centres and not receiving care from the same provider) (Related quotes in appendix 3: 40 to 42)

- Public and doctors' misperception of the role of community pharmacists (Related quotes in appendix 3: 43 to 46)

- Lack of a remuneration system for pharmacy services (Related quotes in appendix 3: 47 and 48)

- Poor patient understanding about the real cost of healthcare (Related quotes in appendix 3: 49 to 51$)$

* This table was created based on the whole information collected as part of the workshop including transcripts, butchers paper, post-it notes and researchers' notes 
Figure 1. Structure of the workshop

Welcome and presentations

(15 minutes)

Project and context overview (15 minutes)

Activity 1. Exploring the needs and gaps in cardiovascular care and the potential roles for community pharmacies

(60 minutes)

a) Discussion in two groups

(30 minutes)

b) General group discussion (30 minutes)

Break (20 minutes)

Activity 2. Identifying and mapping stakeholders (80 minutes)

a) Stakeholder identification in two groups (35 minutes)

b) Stakeholder classification in two groups (30 minutes)

c) General group discussion to reach consensus (15 minutes)

Wrap-up and next steps of the project (10 minutes)

Reflections, close and thanks $(10 \mathrm{~min})$ 


\section{Figure 2. Stakeholder map ${ }^{\ddagger}$}

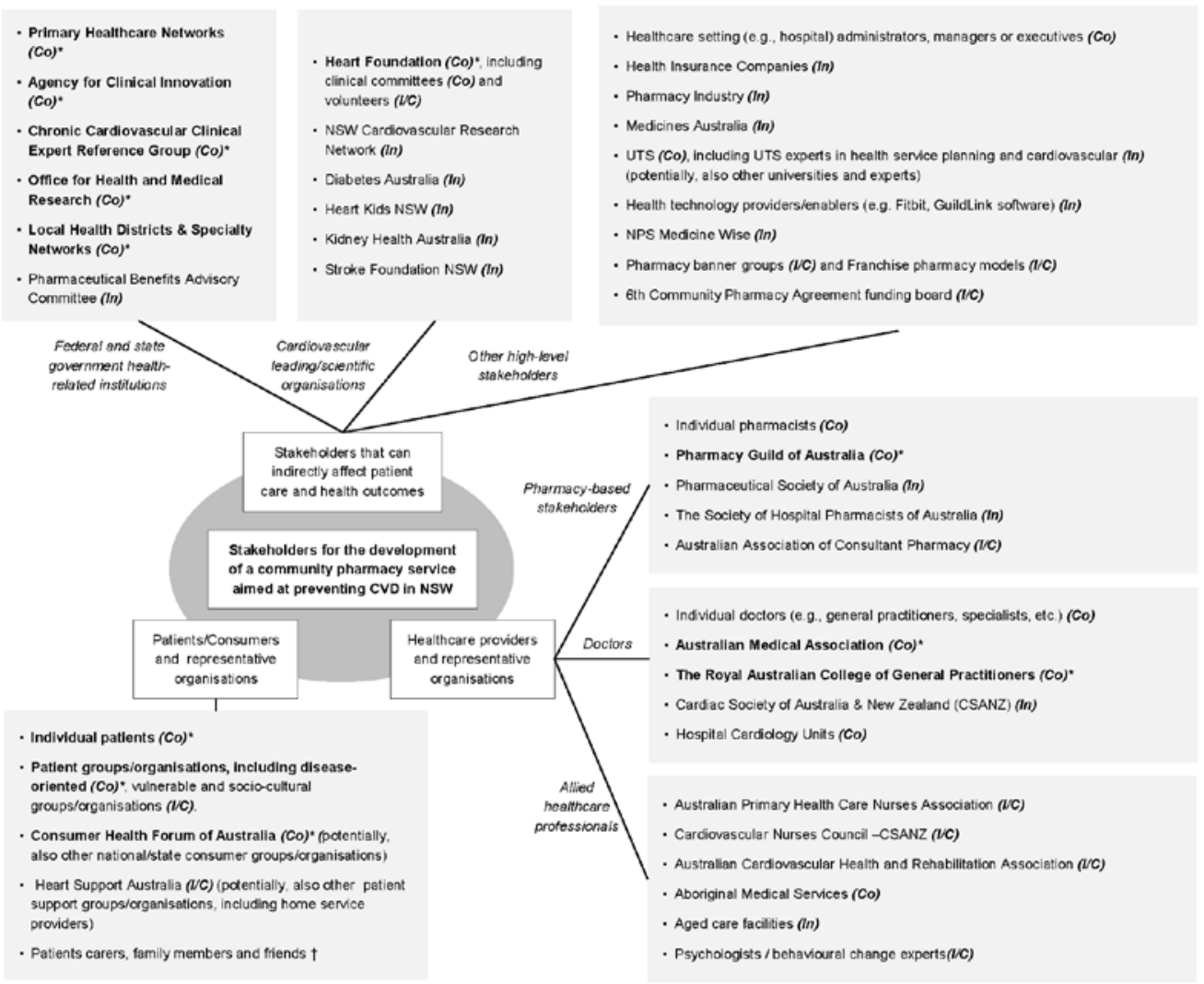

CVD: cardiovascular disease; NSW: New South Wales (Australia); UTS: University of Technology, Sydney; Co: control (i.e., the stakeholder is considered to have the ability to control the development of the service, can prevent it from progressing or help make it happen); In: influence (i.e., the stakeholder is considered to have the ability to influence the development of the service; they have less control but are still important to making it happen); I/C: interest/concern (i.e., stakeholders who may be interested in or concerned with the service but will not significantly impact on whether or not the project goes ahead).

₹ This figure was created based on the whole information collected as part of the workshop including transcripts, butchers paper, post-it notes and researchers' notes

$\dagger$ These stakeholders were included by the researchers based on existing theory

* Stakeholders considered core by the key informants 


\section{Appendix 1: Support material for Activity 1.}

Use the elements in the following table to think about (1) gaps, needs or opportunities in cardiovascular care or (2) potential target ('at risk') populations.

\begin{tabular}{|c|c|}
\hline $\begin{array}{l}\text { Non-modifiable risk } \\
\text { factors }\end{array}$ & $\begin{array}{l}\text { - } \text { Age } \\
\text { - Gender } \\
\text { - Inherited (genetic) disposition }\end{array}$ \\
\hline Behavioural risk factors & $\begin{array}{l}\text { - Tobacco use } \\
\text { - Physical inactivity } \\
\text { - Unhealthy diet } \\
\text { - Harmful use of alcohol }\end{array}$ \\
\hline Metabolic risk factors & $\begin{array}{l}\text { - Overweight and obesity } \\
\text { - Raised blood pressure (hypertension) } \\
\text { - Raised blood glucose (diabetes) } \\
\text { - Raised blood lipids (dyslipidaemia) }\end{array}$ \\
\hline $\begin{array}{l}\text { Other risk factors and } \\
\text { target organ damage } \\
\text { (examples) }\end{array}$ & $\begin{array}{l}\text { - Poverty and low educational status } \\
\text { - Psychological factors (e.g. stress) } \\
\text { - Kidney disease/damage } \\
\text { - Left ventricular hypertrophy }\end{array}$ \\
\hline $\begin{array}{l}\text { Cardiovascular } \\
\text { diseases }\end{array}$ & $\begin{array}{l}\text { - Ischaemic heart disease and coronary artery disease } \\
\text { - Cerebrovascular disease } \\
\text { - Peripheral vascular disease } \\
\text { - Cardiomyopathies } \\
\text { - Cardiac arrhythmias } \\
\text { - Congenital heart disease } \\
\text { - Rheumatic heart disease }\end{array}$ \\
\hline
\end{tabular}


Use the elements in the following table to think about how pharmacy services can help enhance cardiovascular care.

\begin{tabular}{|c|c|}
\hline Role of pharmacists & Examples \\
\hline $\begin{array}{l}\text { Patient education and } \\
\text { counselling }\end{array}$ & $\begin{array}{l}\text { Provide patients with information about health problems, } \\
\text { correct use of medicines, non-pharmacological treatment }\end{array}$ \\
\hline Promote behavioural changes & $\begin{array}{l}\text { Promote healthy lifestyles } \\
\text { Adherence to treatment } \\
\text { Promote self-monitoring }\end{array}$ \\
\hline $\begin{array}{l}\text { Medication } \\
\text { review/assessment }\end{array}$ & $\begin{array}{l}\text { Assess the appropriateness of drugs and treatment } \\
\text { strategies; interactions; costs of treatments; adverse } \\
\text { effects. }\end{array}$ \\
\hline $\begin{array}{l}\text { Assessment of health } \\
\text { outcomes and follow-up }\end{array}$ & $\begin{array}{l}\text { Disease screening } \\
\text { Evaluating the effectiveness and safety of treatments }\end{array}$ \\
\hline $\begin{array}{l}\text { Participation with the } \\
\text { healthcare team }\end{array}$ & $\begin{array}{l}\text { Provision of information to other healthcare professionals } \\
\text { Access and management of the medication history } \\
\text { Development of care protocols }\end{array}$ \\
\hline $\begin{array}{l}\text { Collaborative disease } \\
\text { management }\end{array}$ & $\begin{array}{l}\text { Recommendations to physicians (adjustments in } \\
\text { treatment) } \\
\text { Prescription of drugs according to predefined protocols }\end{array}$ \\
\hline
\end{tabular}


Appendix 2: Brief description of the roles of Australian government-related stakeholders.

\begin{tabular}{|c|c|c|}
\hline Governmental stakeholder & $\begin{array}{l}\text { Brief description of the role (as } \\
\text { described in official web pages) }\end{array}$ & $\begin{array}{l}\text { Consulted web pages and } \\
\text { access date }\end{array}$ \\
\hline $\begin{array}{l}\text { Primary Healthcare Networks } \\
\text { (Federal Government, } \\
\text { Department of Health) }\end{array}$ & $\begin{array}{l}\text { "Primary Health Networks (PHNs) } \\
\text { have been established with the key } \\
\text { objectives of increasing the } \\
\text { efficiency and effectiveness of } \\
\text { medical services for patients, } \\
\text { particularly those at risk of poor } \\
\text { health outcomes, and improving } \\
\text { coordination of care to ensure } \\
\text { patients receive the right care in } \\
\text { the right place at the right time" }\end{array}$ & $\begin{array}{l}\text { http://www.health.gov.au/interne } \\
\text { t/main/publishing.nsf/Content/pri } \\
\text { mary Health Networks } \\
\text { [accessed 08/06/2016] }\end{array}$ \\
\hline $\begin{array}{l}\text { Agency for Clinical Innovation } \\
\text { (State government, NSW } \\
\text { Health) }\end{array}$ & $\begin{array}{l}\text { "The Agency for Clinical Innovation } \\
(\mathrm{ACl}) \text { works with clinicians, } \\
\text { consumers and managers to } \\
\text { design and promote better } \\
\text { healthcare for NSW" }\end{array}$ & $\begin{array}{l}\text { http://www.aci.health.nsw.gov.a } \\
\text { u/about-aci/collaboration- } \\
\text { innovation-better-healthcare } \\
\text { [accessed 08/06/2016] }\end{array}$ \\
\hline $\begin{array}{l}\text { Chronic Cardiovascular Clinical } \\
\text { Expert Reference Group (State } \\
\text { government, NSW Health) }\end{array}$ & $\begin{array}{l}\text { "The Chronic Cardiovascular } \\
\text { Clinical Expert Reference Group } \\
\text { (CV CERG) is a sub-committee of } \\
\text { the Cardiac Network focused on } \\
\text { improving the management of } \\
\text { people with chronic cardiovascular } \\
\text { conditions" }\end{array}$ & $\begin{array}{l}\text { http://www.aci.health.nsw.gov.a } \\
\underline{\text { u/?a=145863 }} \\
\text { [accessed 08/06/2016] }\end{array}$ \\
\hline $\begin{array}{l}\text { Office for Health and Medical } \\
\text { Research (State government, } \\
\text { NSW Health) }\end{array}$ & $\begin{array}{l}\text { "The Office for Health and Medical } \\
\text { Research was established to } \\
\text { implement to ten year strategy for } \\
\text { NSW health and medical } \\
\text { research." "The ten year NSW } \\
\text { Health and Medical Research }\end{array}$ & $\begin{array}{l}\underline{\text { http://www.health.nsw.gov.au/o }} \\
\underline{\text { hmr/Pages/ohmr-history.aspx }} \\
\text { [accessed 08/06/2016] }\end{array}$ \\
\hline
\end{tabular}




\begin{tabular}{|c|c|c|}
\hline & $\begin{array}{l}\text { Strategic Plan identifies how NSW } \\
\text { can position itself as an important } \\
\text { contributor to the international } \\
\text { health and medical research } \\
\text { sector" }\end{array}$ & \\
\hline & $\begin{array}{l}\text { "To encourage collaboration, } \\
\text { sharing and efficient use of } \\
\text { resources, the Office for Health } \\
\text { and Medical Research (OHMR) is } \\
\text { developing resources to encourage } \\
\text { a state-wide approach to key } \\
\text { infrastructure" }\end{array}$ & $\begin{array}{l}\underline{\text { http://www.health.nsw.gov.au/o }} \\
\underline{\text { hmr/Pages/resources.aspx }} \\
\text { [accessed 08/06/2016] }\end{array}$ \\
\hline $\begin{array}{l}\text { Local Health Districts \& } \\
\text { Specialty Networks (State } \\
\text { government, NSW Health) }\end{array}$ & $\begin{array}{l}\text { "NSW Health has fifteen Local } \\
\text { Health Districts and three Specialty } \\
\text { Networks covering New South } \\
\text { Wales...Local Health Districts and } \\
\text { Specialty Networks are established } \\
\text { to operate public hospitals and } \\
\text { institutions and provide health } \\
\text { services to communities within } \\
\text { geographical areas or a defined } \\
\text { patient population for Specialty } \\
\text { Networks" }\end{array}$ & $\begin{array}{l}\frac{\text { http://www.health.nsw.gov.au/hh }}{\text { d/boards/Pages/default.aspx }} \\
\text { [accessed 08/06/2016] }\end{array}$ \\
\hline $\begin{array}{l}\text { Pharmaceutical Benefits } \\
\text { Advisory Committee (Federal } \\
\text { Government, Department of } \\
\text { Health) }\end{array}$ & $\begin{array}{l}\text { "The PBAC is an independent } \\
\text { expert body appointed by the } \\
\text { Australian Government. Its primary } \\
\text { role is to recommend new } \\
\text { medicines for listing on the PBS*. } \\
\text { No new medicine can be listed } \\
\text { unless the committee makes a } \\
\text { positive recommendation" } \\
\text { *PBS: Pharmaceutical Benefits } \\
\text { Scheme }\end{array}$ & $\begin{array}{l}\text { http://www.pbs.gov.au/info/indu } \\
\underline{\text { stry/listing/participants/pbac }} \\
\text { [accessed 08/06/2016] }\end{array}$ \\
\hline
\end{tabular}




\section{Appendix 3: Selected quotes regarding the identification of needs and gaps in cardiovascular care, community pharmacists' roles and the factors that can hinder the implementation of CPS}

Needs and gaps in current cardiovascular care

1. "Patients who get generics or brands of different generics are actually getting confused with what medication they do take. Because they all look different. It's not like I used to take the green one, now you've given me a pink one. You've given me the wrong stuff. They don't even know the criteria under which they should accept a generic"

2. "Then they go and get a generic version which is a completely different colour and they're completely thrown. They think, but I took a blue one, now it's a yellow one. That's all they know, colours and shapes. I think that's actually another issue for taking medications. The plethora of different generics and brand names"

3. "What I need to have is an accurate medicines list in their wallet"

4. "There can be cases where no one other than that patient really knows their full medical picture and their full pharmacological profile as well"

5. "And then, they stopped their medicines for various reasons and things like that. They haven't understood, they think they're cured. Once they're in the hospital, they think they're cured because they had a stent or a surgery, but especially the stent. They don't understand, and they don't see the need to get cardiac rehab or getting any further education and things like that"

6. "All those sort of things [blood pressure, cholesterol, diabetes, weight and smoking] go in there and when we talk about one disease, then that's at the risk of ignoring the half a dozen risk factors that are going to contribute to that disease."

7. "I think it's [cardiovascular disease] also perceived as self-inflicted problem and therefore you don't admit to it"

8. "It's [cardiovascular disease] shameful"

9. "It's the psychology of the perception of the disease. You can become literate about the impact of heart disease, but subconsciously do you still think, oh well, I've brought it on myself" 
10. "I think everyone's got their eye on the big scary cancer. There's so much promotion about it on television, by sports heroes, by anyone with a high profile name. How many people do you actually see on television talk, that that's a high profile person talk about ..." [talking about cardiovascular disease]

11. "When a young woman has heart attack it's shock horror, and yet more women die of heart disease than they do of breast cancer. How many people know that?"

12. "The other thing that people come into pharmacy for is just to get their blood pressure checked."

13. "Maybe if we lumped other chronic diseases in the same boat, so that they could see that actually other chronic disease states are brought about by the same lifestyle factors"

14. "Vaccination and immunisation. I think immunization is good in patients that are at risk of ... or have a cardiovascular disease condition, ensuring that we immunize them"

15. "We talked about the patients, the vast majority who miss out on cardiac rehab, either by the fact that if they don't have accessible to them, or they chose not to go. Therefore they miss out on those sort of education sessions that are typically run through cardiac rehab"

16. "The different setting [metropolitan vs rural or big cities vs small towns] is really going to determine some of these issues [pharmacists knowing the patients and their medication, pharmacists knowing patient's doctors, patients going consistently to the same pharmacy or doctor]"

17. "A lot of things [services] are very focused and centric on the metropolitan area"

18. "I suppose our role [healthcare professionals] is to try and help them navigate through the health system"

Associated role of community pharmacists

19. "I think again it comes down to health education between the pharmacist, between the doctors, between the hospitals, [inaudible], specialists, and GPs"

20. "I know there's a bit of work done with medication reviews, extending on the home medication reviews, but discharge medication reviews. A patient comes out, pharmacist then 
has a look at their medication, sort of draws that gap between the community care with the GPS"

21. "...the other thing that I think doctors are atrocious at and pharmacists are particularly good at, is drug interactions and toxicities. I think that's something, we're always suspicious that our patients are making up their side effect to whatever medication we prescribe [...]l think that the pharmacists are in a much better place to look across the whole range of medications"

22. "Then I think there's that monitoring magnate, whether it's patient compliance, or bridging the gap in terms of doing more HMR [home medication review] reports where you actually go in somebodies home and have a look at the medication they're on. You can actually physically see what medication they're taking if they're not complying"

23. "The community pharmacy could really fill the gap here [not all patient's going to cardiac rehab] in their local context if they know what occurs with patients who might have any cardiovascular ... it doesn't just have to be heart attack. It can be heart surgery, valve surgery or a surgery like that"

24. "Every patient needs to receive a comprehensive list of all of their pharmacopeia on a piece of paper from a health care provider, which will be their GP, hopefully, and that should be then shared all to them to pharmacies so that they can crosscheck that, and then the pharmacists role is to check any potential interactions"

25. "[list of medications]... That would be great if that was provided by the pharmacists"

26. "What I need to have is an accurate medicines list in their wallet. How they get that, there might be different ways to get that. It may be that the pharmacist provided that for them, or it may be that the pharmacist just needs to check it, because we don't want to disempower patients"

27. "It's the role, enabling role to make sure they've got what they need to have the autonomy?"

28. "I think so, and recognizing the people who need help or more help than those who don't need so much help, so that's not a blank or for everybody."

29. "...also mentioned about the potential for using the pharmacist to fill in the gaps in terms of immunisation for people that ordinarily aren't getting the flu vac immunisation that should be having it" 
30. "We just thought that perhaps there's a potential for more involvement for community pharmacists in multidisciplinary cardiac rehab. We did say in particular like in more regional and rural areas, that might be an important role"

31. "I think that's actually screening patients who are not diagnosed and then sending them through to the GP, because you see them quite ... I think, so there's for the diagnosis because I don't think that, you know obviously pharmacy doesn't have a role to play in diagnosis, but you certainly could help screen"

Factors that can hinder the integration of cardiovascular community pharmacy services into practice

32. "You think, right, you've just spent thousands of dollars trying to get this person stabilised and then they walk out the door, because it's quitting time, and the follow through hasn't actually occurred"

33. "There's no way that the pharmacist is necessarily aware that the patient has perhaps been in hospital recently for an MI [myocardial infarction] or anything like that unless it's communicated directly from the patient"

34. "There can be cases where no one other than that patient really knows their full medical picture and their full pharmacological profile as well"

35. "There's no sort of loop where the pharmacist can go back to the doctor in an easy way to say, why is this prescription for this? They just have this complete information vacuum that they're operating in. It's just what's on that piece of prescription paper"

36. "...the prescription pad, as we call it, as a form of communication between the doctor and the pharmacist is very inadequate. It doesn't tell you anything"

37. “...because I don't know what you told them, so I'm not going tell them anything, because I don't want to contradict you. If I tell them something then it might be contradicting you"

38. "The main reason we're not empowered [pharmacists] to deal with in these situations is lack of communication with doctors, lack of accessibility" 
39. "We are in our own silos of medical, pharmacy, hospital and there isn't any ... Any information communication is often scrawled or written indecipherably between doctors particularly, and so I think it is a communication issue"

40. "They do go to at least 2 pharmacies these days, they go to the discount one for their herbals and cheaper whatever's plus their regular sort of family pharmacy"

41. "I think people are going to more and more different pharmacies and different GPS as well. I think people don't necessarily stick to the same GP"

42. "Also the issue to do with multiple doctors and multiple pharmacists. There's no consistency. There can be cases where no one other than that patient really knows their full medical picture and their full pharmacological profile as well"

43. "We also established there was a gap in terms of the turf war, and the understanding for the GP's and the pharmacists in each other's roles"

44. "I think it's more of an issue with primary health care providers, so GPs are going to be more ... Feel more under threat if pharmacists particularly go into health prescription, we're talking about writing scripts and things"

45. "...that could be a big issue in terms of making any recommendations or changes. I think that's why I was sort of saying there needs to be a reorientation and re-education of the role pharmacists to doctors"

46. "I think that's what, from the public's point of view, the education needs to be an awareness of pharmacy as a shop, versus pharmacy as health promotion"

47. "The other thing was that there's a lack of Medicare rebates for any kind of additional roles for the pharmacy"

48. "A lot of the services that you actually deliver, you're not remunerated for like if they sit down with their doctor or GP; you're only remunerated on that product that you sell"

49. "You get the same patients that spend hundreds of dollars on complimentary medicine. Then complaint that they've paying $\$ 10$ for antibiotics"

50. "That's because we've become used to having all of our health costs, not all but a huge portion, because they don't understand the true cost, subsidised" 
51. "That could be part of the opportunity for education. To educate people in the true cost of health, from every service providers point of view, whether it be the cost of pharmaceutical, the cost of the doctors time, the true cost of the doctors time, and the true cost of the primary health providers time, the GP" 